\title{
Analysis of the Seismic Performance of a Two-Span Specially Shaped Column Frame
}

\author{
Zhen-chao Teng (D), Tian-jia Zhao $\mathbb{D}$, and Yu Liu $(\mathbb{D}$ \\ College of Civil Engineering and Architecture, Northeast Petroleum University, No. 99, XueFu Road., Daqing 163318, China \\ Correspondence should be addressed to Yu Liu; 651988938@qq.com
}

Received 7 March 2019; Revised 28 April 2019; Accepted 19 May 2019; Published 18 July 2019

Academic Editor: Claudio Mazzotti

Copyright (c) 2019 Zhen-chao Teng et al. This is an open access article distributed under the Creative Commons Attribution License, which permits unrestricted use, distribution, and reproduction in any medium, provided the original work is properly cited.

\begin{abstract}
In traditional building construction, the structural columns restrict the design of the buildings and the layout of furniture, so the use of specially shaped columns came into being. The finite element model of a reinforced concrete framework using specially shaped columns was established by using the ABAQUS software. The effects of concrete strength, reinforcement ratio, and axial compression ratio on the seismic performance of the building incorporating such columns were studied. The numerical analysis was performed for a ten-frame structure with specially shaped columns under low reversed cyclic loading. The load-displacement curve, peak load, ductility coefficient, energy dissipation capacity, and stiffness degradation curve of the specially shaped column frame were obtained using the ABAQUS finite element software. The following three results were obtained from the investigation: First, when the strength of concrete in the specially shaped column frame structure was increased, the peak load increased, while the ductility and energy dissipation capacity weakened, which accelerated the stiffness degradation of the structure. Second, when the reinforcement ratio was increased in the specially shaped column frame structure, the peak load increased and the ductility and energy dissipation capacity also increased, which increased the stiffness of the structure. Third, when the axial compression ratio was increased in the structure, the peak load increased, while ductility and energy dissipation capacity reduced, which accelerated the degradation of structural stiffness.
\end{abstract}

\section{Introduction}

With the increasingly improved living quality in China, popular expectation for improvements in the quality of buildings has increased. In traditional buildings, the structural columns tend to limit interior design and furniture layout and reduce the effective utilization of the indoor area [1-3]. While assuring structural safety, structure designers innovate continuously and enrich the form and style of buildings, which become more beautiful, flexible, and convenient. Therefore, specially shaped columns have emerged, which at the time of writing is a new form of column that has been applied widely in new-type buildings [4-6]. Specially shaped columns include L-shaped columns, T-shaped columns, and columns with crossshaped cross sections, amongst which columns with crossshaped cross sections have been the most applied. Specially shaped columns effectively avoid obvious structural columns within the building, make the layout of the entire building more beautiful, and effectively increase the usable area within the building [7-9]. However, academic verification of theories relating to specially shaped column structures currently is scarce in China. Therefore, it has become important to study the mechanical properties of specially shaped column structures $[10,11]$. Numerical models of reinforced concrete frame structures with specially shaped columns were established using the ABAQUS FE software, based on which the influential relationships were obtained between concrete strength, reinforcement ratio, and axial compression ratio on their seismic performance [12-15].

\section{Finite Element (FE) Modeling}

2.1. Specimen Design. In this study, the main input parameters were concrete strength, reinforcement ratio, and 
axial compression ratio. According to the requirements of Technical Specification for Concrete Structures with Specially Shaped Columns(JGJ 149-2006) [16], the sectional thickness of specially shaped columns should not be less than $200 \mathrm{~mm}$ and the height of such columns should not be less than $500 \mathrm{~mm}$. Therefore, 20 specially shaped reinforced concrete columns were designed. As shown in Table 1, the effects of these three working conditions on the seismic performance of the columns, comprising 10 cross-shaped columns and 10 T-shaped columns, were explored, and all were $3 \mathrm{~m}$ in height. In order to facilitate the application of horizontal displacement and axial load to all parts of the column section, a cushion plate was set at the top of the column in the range of $200 \mathrm{~mm}$. The thickness of cross-shaped column limbs was $200 \mathrm{~mm}$, the height of the limbs was $800 \mathrm{~mm}$, the thickness of T-shaped column limbs was $200 \mathrm{~mm}$, the height of the limbs was $500 \mathrm{~mm}$ and $800 \mathrm{~mm}$, and the thickness of stirrups (see diagram) and the concrete outermost cover layer was $20 \mathrm{~mm}$. The shape and size of the specimens and the reinforcement diagram are shown in Figure 1.

In order to study effects of concrete strength, reinforcement ratio, and axial compression ratio on the seismic performance of frame structures with specially shaped columns, according to the design requirements of Technical Specification for Concrete Structures with Specially Shaped Columns (JGJ 149-2006) [16], the strength grade of the concrete should be between C25 and C50, the diameter of longitudinal reinforcements should be between $14 \mathrm{~mm}$ and $25 \mathrm{~mm}$, the reinforcement ratio of the stressed reinforcements should be between $0.8 \%$ and $3 \%$, and the limit value of the axial compression ratio of $\mathrm{T}$-shaped columns and cross-shaped columns should be divided by 0.65 and 0.70 , respectively.

Ten specimens with various concrete strengths (C30, C35, C40, and C45), reinforcement ratios (1.09\%, 1.35\%, $1.63 \%$, and $2.1 \%)$, and axial compression ratios $(0.2,0.35$, 0.5 , and 0.65 ) were designed for use in the present investigation. The loading models then were calculated and analyzed using the ABAQUS finite element software, from which the load-displacement curves, peak loads, ductility factors, energy dissipation capacities, and stiffness degradation curves of specially shaped column frames were obtained. Its calculations were made according to equation (1) and Figure 2. The parameters of the simulated specimens are summarized in Table 1.

$$
E=\frac{S_{\triangle \mathrm{ABC}}+S_{\triangle \mathrm{CDA}}}{S_{\triangle \mathrm{OBE}}+S_{\triangle \mathrm{ODF}}}
$$

2.2. Development of the Model. Finite element numerical simulation is a recognized research tool. During the process of building a finite element model, the damage plasticity model was selected to simulate concrete. Plastic damage models can simulate mechanical phenomena such as the cracking and crushing of concrete materials. The model can be combined with isotropic damage elasticity. The isotropic tensile and compressive plastic model, which represents the inelastic behavior of concrete, is a continuum damage model based on plasticity. The combined model exhibits better convergence [16-19].

In order to verify the validity of the model, a simplified mechanical model was established in ABAQUS according to the test results in the reference literature and boundary conditions and corresponding loading methods were used to restrict the bottom of the shaped columns to six degrees of freedom. That is to say, the bottom of the column can neither rotate nor move, and the node of the cushion plate on the top of the column can restrict three degrees of freedom [20-22]. It is impossible, therefore, for the column to rotate in any direction. The boundary conditions are illustrated in Figure 3.

A classic BKIN (bilinear kinematic) hardening plasticity model was applied to describe the constitutive relationship of reinforcements. The reinforcements were merged into a reinforcement cage that was built inside the whole column region. The specimen and boundary conditions were set up and simplified according to the practical situation of testing, which ensured that the simulation results would be closer to test values [23, 24]. A pictorial illustration showing the procedure for the establishment of the model is presented in Figure 4.

2.3. Material Parameters. Parameters related to material properties, such as elastic modulus, Poisson's ratio, and density, are listed in Table 2.

\section{Experimental Verification of the FE Model}

3.1. A Survey of Existing Tests. The test data from the literature $[25,26]$ for specific parameters are shown in Table 3.

3.2. Result Verification. Based on the experimental test data, ABAQUS was used to establish a finite element model with the same control parameters, and the hysteretic performance of the resulting structure was analyzed. The hysteresis curve, skeleton curve, and test curve can be compared, as shown in Figure 5 .

As shown in Figure 5, the trend variation of the test curves was consistent with that of the finite element simulation curves; the difference of the ultimate load was small, and the skeleton curves were in close agreement. It can be observed that the finite element simulation response was good, and it had certain rationality and accuracy.

\section{Finite Element Analysis}

4.1. Concrete Strength. The "hysteresis curve" and "skeleton curve" were defined as follows: The "hysteresis curve" refers to the deformation response of a structure under repeated loading and unloading. It reflects the deformation characteristics, stiffness degradation, and energy consumption of the structure. This response is the basis for determining the restoring force model and carrying out nonlinear seismic response analysis. It is also known as the "restoring force curve." The "skeleton curve" refers to the curve obtained by translating a section of a stress-strain 
TABLE 1: Parameters of the simulated specimens.

\begin{tabular}{|c|c|c|c|c|c|c|c|c|}
\hline \multirow[b]{2}{*}{ Specimen } & \multicolumn{4}{|c|}{ Cross-shaped columns } & \multicolumn{4}{|c|}{ T-shaped columns } \\
\hline & $\begin{array}{l}\text { Axial } \\
\text { compression } \\
\text { ratios }\end{array}$ & $\begin{array}{l}\text { Reinforcement } \\
\text { ratios (\%) }\end{array}$ & $\begin{array}{l}\text { Diameter } \\
(\mathrm{mm})\end{array}$ & $\begin{array}{l}\text { Concrete } \\
\text { strengths }\end{array}$ & $\begin{array}{c}\text { Axial } \\
\text { compression } \\
\text { ratios }\end{array}$ & $\begin{array}{l}\text { Reinforcement } \\
\text { ratios }(\%)\end{array}$ & $\begin{array}{l}\text { Diameter } \\
(\mathrm{mm})\end{array}$ & $\begin{array}{l}\text { Concrete } \\
\text { strengths }\end{array}$ \\
\hline K-1 & 0.35 & 1.63 & 22 & $\mathrm{C} 30$ & 0.35 & 1.74 & 20 & $\mathrm{C} 30$ \\
\hline K-2 & 0.35 & 1.63 & 22 & C35 & 0.35 & 1.74 & 20 & C35 \\
\hline $\mathrm{K}-3$ & 0.35 & 1.63 & 22 & $\mathrm{C} 40$ & 0.35 & 1.74 & 20 & $\mathrm{C} 40$ \\
\hline K-4 & 0.35 & 1.63 & 22 & $\mathrm{C} 45$ & 0.35 & 1.74 & 20 & $\mathrm{C} 45$ \\
\hline K-5 & 0.35 & 1.09 & 18 & C30 & 0.35 & 1.22 & 16 & C30 \\
\hline K-6 & 0.35 & 1.35 & 20 & C30 & 0.35 & 1.47 & 18 & C30 \\
\hline $\mathrm{K}-7$ & 0.35 & 2.10 & 25 & C30 & 0.35 & 2.04 & 22 & $\mathrm{C} 30$ \\
\hline K-8 & 0.2 & 1.63 & 22 & C30 & 0.2 & 1.74 & 20 & $\mathrm{C} 30$ \\
\hline K-9 & 0.5 & 1.63 & 22 & C30 & 0.5 & 1.74 & 20 & C30 \\
\hline K-10 & 0.65 & 1.63 & 22 & C30 & 0.65 & 1.74 & 20 & C30 \\
\hline
\end{tabular}

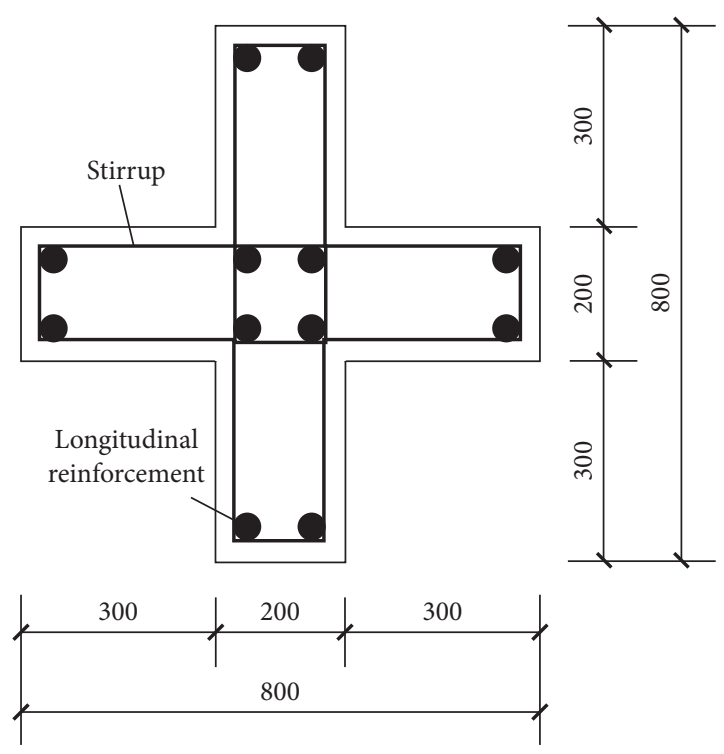

(a)

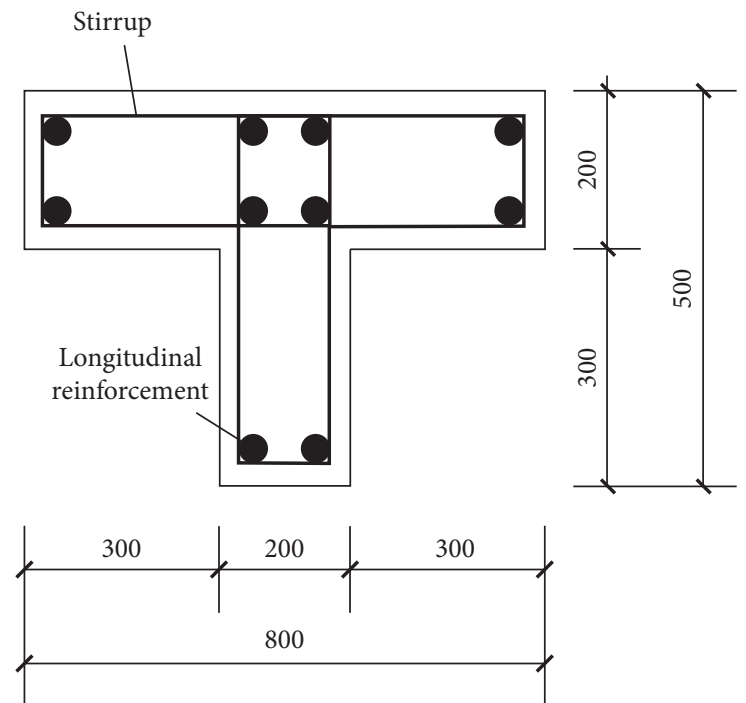

(b)

Figure 1: Cross sections of the specially shaped columns. (a) Cross-shaped columns. (b) T-shaped columns.

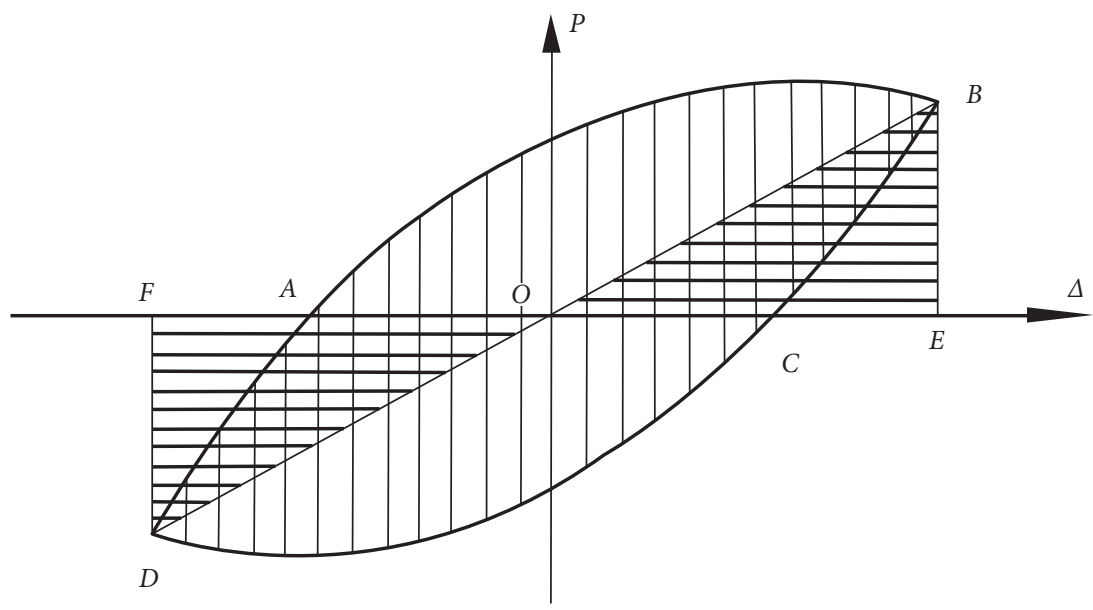

FIGURE 2: Load-displacement hysteresis energy dissipation curve. 


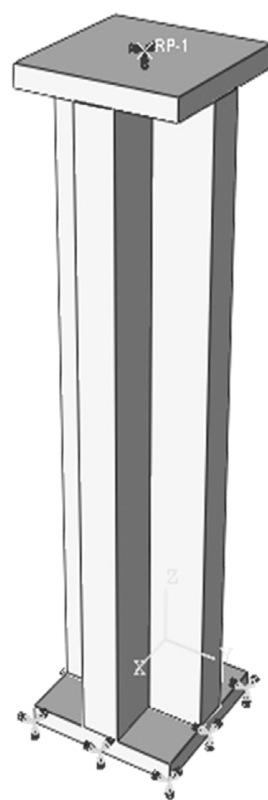

(a)

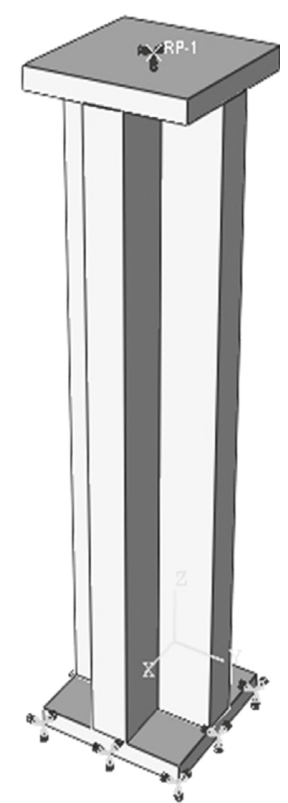

(b)

Figure 3: Boundary condition schematic. (a) Cross-shaped columns. (b) T-shaped columns.
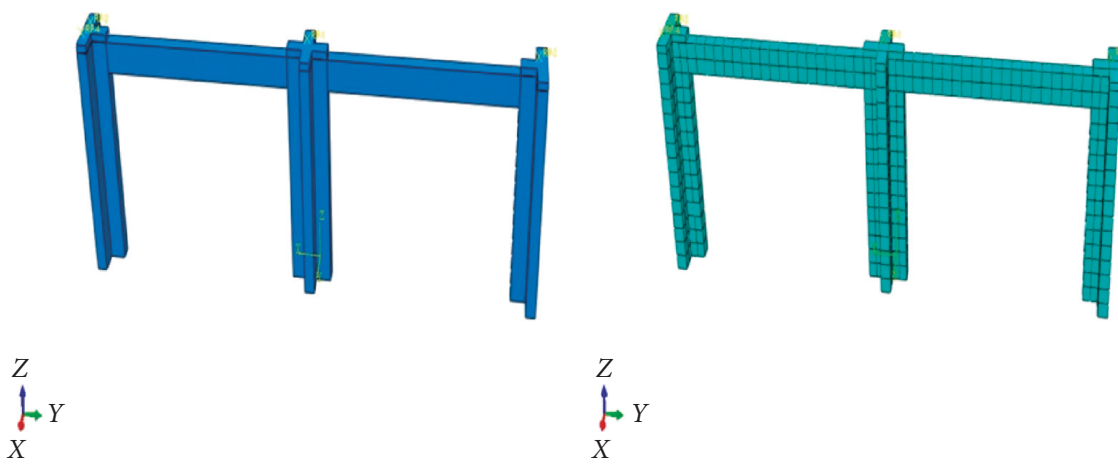

(a)
$\underset{X}{Z}{ }_{X}$

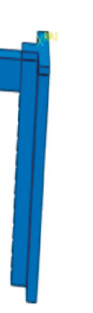

(b)

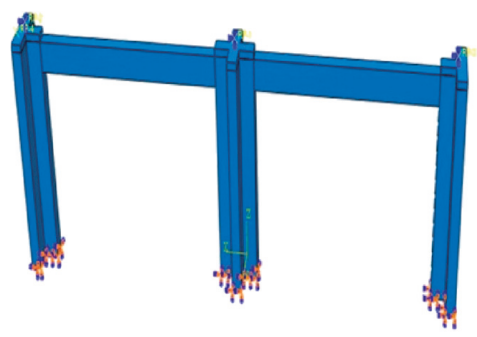

Z $\hat{X}^{\prime} Y$

(c)

Figure 4: Schematic diagrams illustrating the procedure for model establishment. (a) Model of a cross-shaped column. (b) Mesh of the cross-shaped column. (c) Addition of constraints.

TABLE 2: Summary of material parameters.

\begin{tabular}{|c|c|c|c|c|}
\hline Material & Type of material & Elastic modulus $\left(\mathrm{N} / \mathrm{mm}^{2}\right)$ & Poisson's ratio & Density $\left(\mathrm{kg} / \mathrm{m}^{3}\right)$ \\
\hline Reinforcement & HRB335 & $2.0 \times 10^{5}$ & 0.3 & $7.85 \times 10^{3}$ \\
\hline Concrete & $\begin{array}{l}\text { C30 } \\
\text { C35 } \\
\text { C40 } \\
\text { C45 }\end{array}$ & $\begin{array}{l}3.00 \times 10^{4} \\
3.15 \times 10^{4} \\
3.25 \times 10^{4} \\
3.35 \times 10^{4}\end{array}$ & 0.2 & $2.5 \times 10^{3}$ \\
\hline
\end{tabular}

TABle 3: Test parameters.

\begin{tabular}{lccccc}
\hline Specimen & $\begin{array}{c}\text { Concrete } \\
\text { strengths }\end{array}$ & $\begin{array}{c}\text { Reinforcement } \\
\text { type }\end{array}$ & $\begin{array}{c}\text { Diameter of the reinforcement } \\
(\mathrm{mm})\end{array}$ & $\begin{array}{c}\text { Axial compression } \\
\text { ratios }\end{array}$ & $\begin{array}{c}\text { Thickness of the protective layer } \\
(\mathrm{mm})\end{array}$ \\
\hline$+\mathrm{Z}-1$ & C50 & HRB500 & 16 & 0.39 & 25 \\
TZ-2 & C40 & HRB335 & 12 & 0.18 & 20 \\
\hline
\end{tabular}

curve loaded in the same direction (tension or compression) beyond the maximum stress of the previous load [27-30].
4.1.1. Effects of Concrete Strength on the Energy Dissipation Performance of the Frame. The hysteresis curves of the reinforced concrete frame structure with shaped columns, 


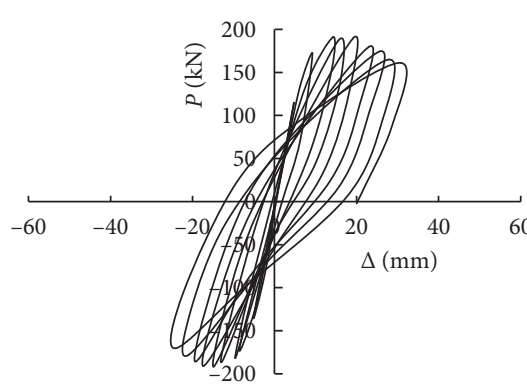

(a)

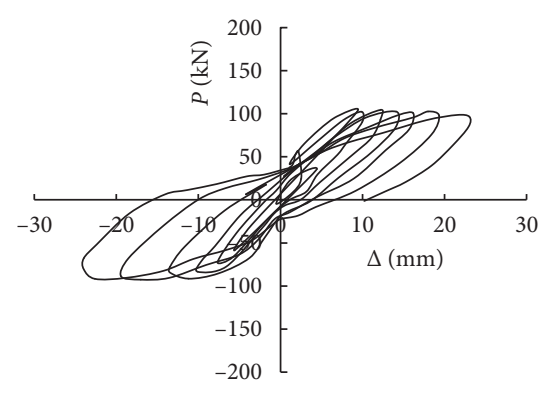

(d)

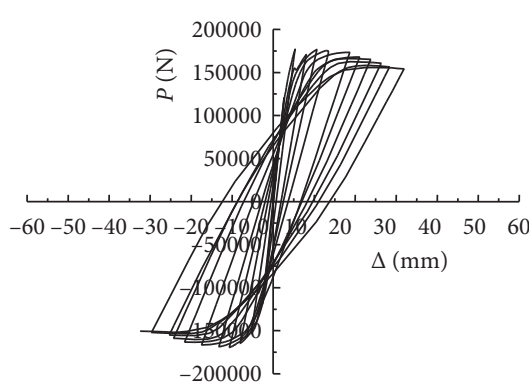

(b)

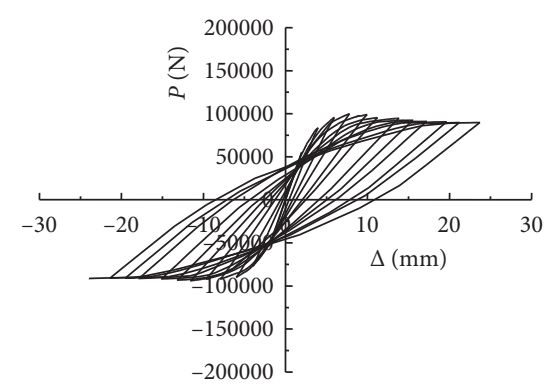

(e)

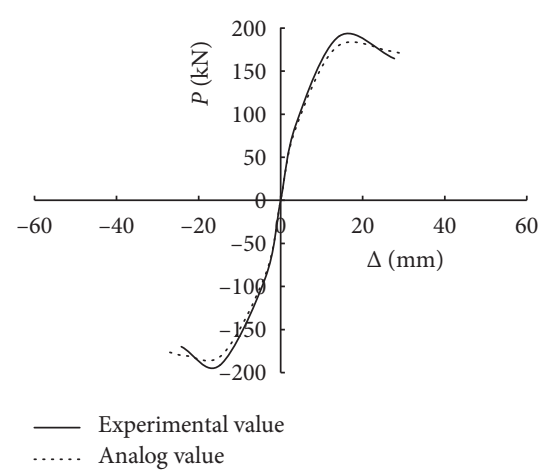

(c)

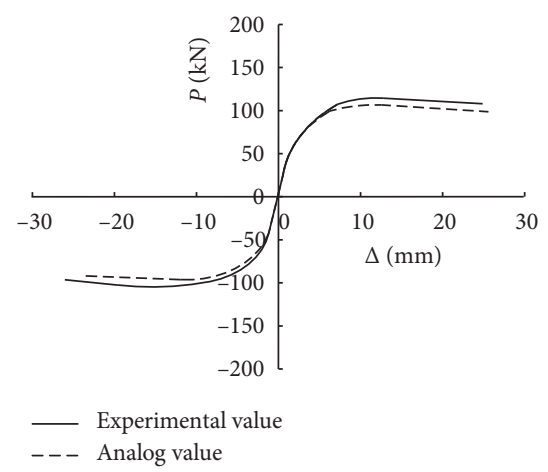

(f)

Figure 5: Hysteresis curves of + Z-1 and TZ-2. (a) + Z-1 test hysteresis curve. (b) + Z-1 simulated hysteresis curve. (c) + Z-1 skeleton curve comparison. (d) TZ-2 test hysteresis curve. (e) TZ-2 simulated hysteresis curve. (f) TZ-2 skeleton curve comparison.

with various concrete strength levels, under low reversed cyclic loading, are shown in Figure 6. The corresponding skeleton curves that were obtained are shown in Figure 7.

As shown in Figure 6, the specimens had strong plastic deformation capacities and good seismic performance and energy dissipation capacities. As is evident, with the increase in the concrete strength of the reinforced concrete frame structure with shaped columns, its ductility became progressively lower.

According to Figure 6, the coefficients of energy dissipation of the shaped-column-reinforced concrete frame structure were calculated, based on which curves reflecting the relationship between various concrete strength levels and the corresponding coefficients of energy dissipation of the frame were obtained, as shown in Figure 8.

According to Figure 8, the relationship between the energy dissipation curves of reinforced concrete frame structures with specially shaped columns now can be deduced. The curves indicate that energy dissipation occurs mainly after frame yielding. During the later period of loading, the energy dissipation coefficient slowly increased, and even decreased, because of accumulating damage. After this period, in essence, the energy dissipation coefficient gradually increased with the increase in the displacement. Relative to a single specimen, the amplitude change resulting from any increase in the energy dissipation coefficient was larger, indicating that the increase in concrete strength reduces the energy dissipation capacity of the reinforcement frame.
4.1.2. Effects of Concrete Strength on the Deformation Performance of the Frame. According to Figure 7, ductility coefficients were calculated, based on which curves were obtained reflecting the relationship between various concrete strength levels and the ductility coefficients of the compound structure, as shown in Figure 9.

By contrast, from curves shown in Figure 9, it can be observed that, with an increase in concrete strength levels, the deformation performance of the frame gradually decreased.

4.1.3. Effects of Concrete Strength on the Stiffness Degradation Performance of the Frame. According to equation (2) and Figure 6, variations in the stiffness values of a reinforced concrete frame with shaped columns were calculated, based on which curves reflecting the relationship between concrete strength and degradation in stiffness of the frame were obtained when displacement varied, as shown in Figure 10. [31]:

The probability density function can be stated as follows

$$
f(x)=\frac{k(\omega-x)^{k-1}}{k(\omega-\varepsilon)^{k}} \times e^{-((\omega-x) /(\omega-\varepsilon))^{k}} .
$$

As shown in Figure 10, the stiffness degradation curves of every reinforced concrete frame with shaped columns can be divided into three different stages, i.e., the rapid descent stage, the descent stage, and the slow descent stage. Keeping the reinforcement ratios and axial compression ratios constant, with increasing concrete strength, the initial 


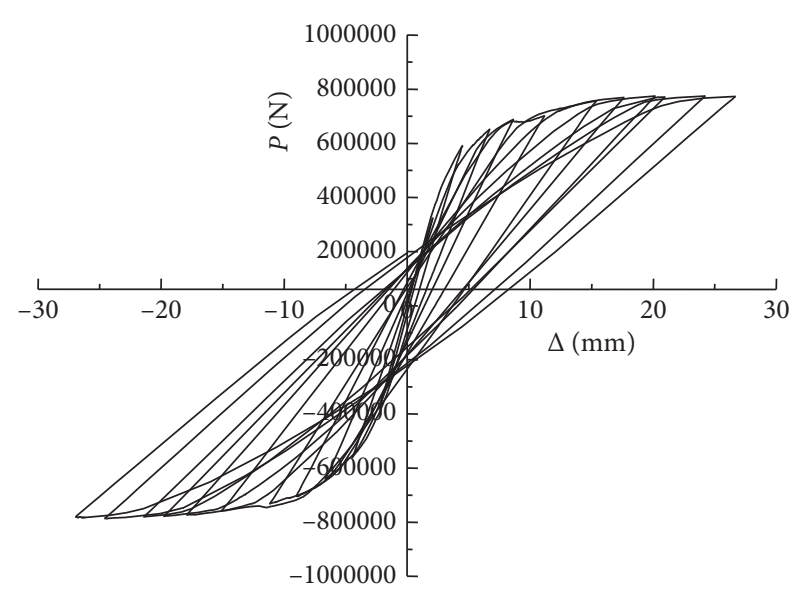

(a)

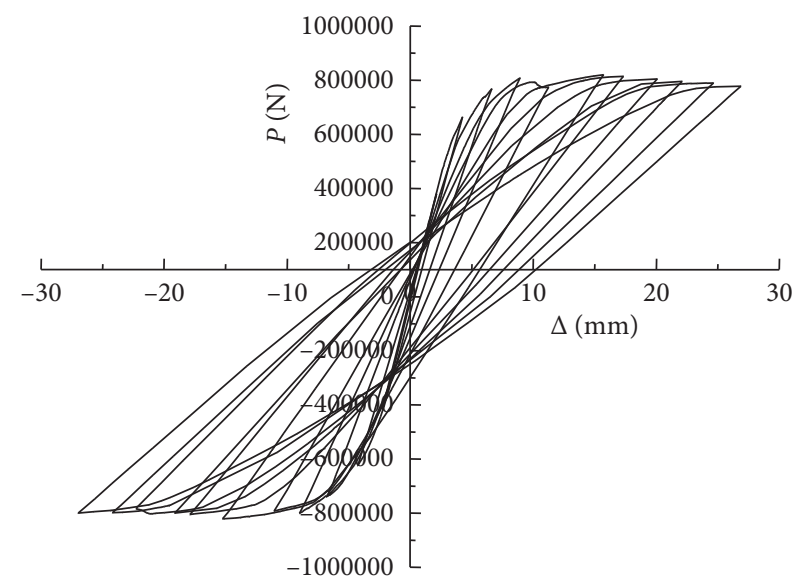

(c)

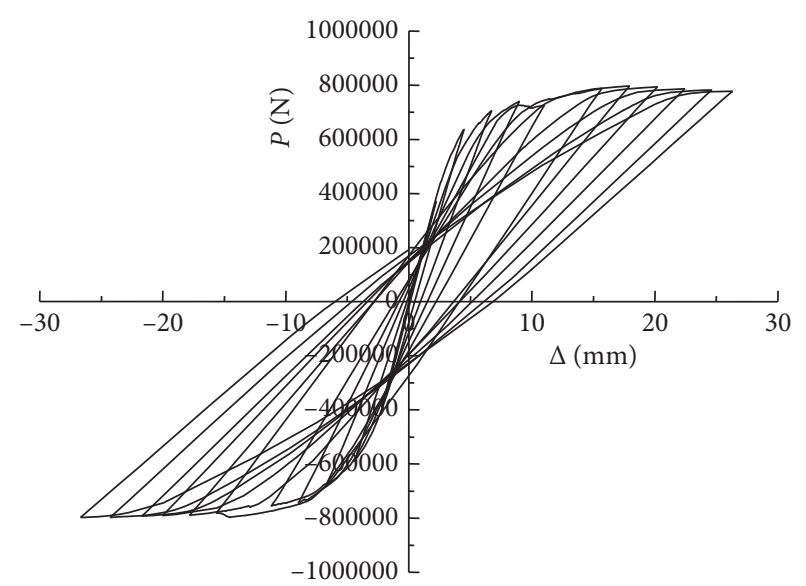

(b)

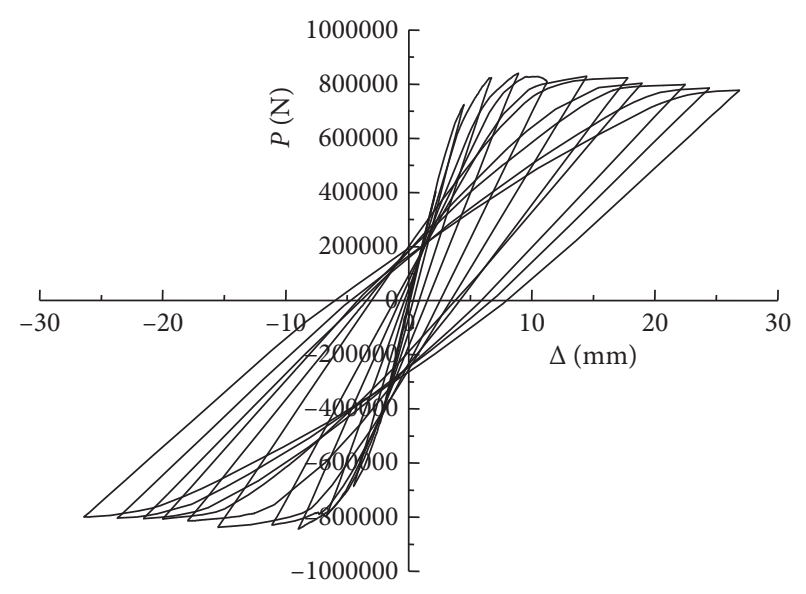

(d)

Figure 6: Hysteresis curves of frames with various concrete strength levels. (a) K-1. (b) K-2. (c) K-3. (d) K-4.

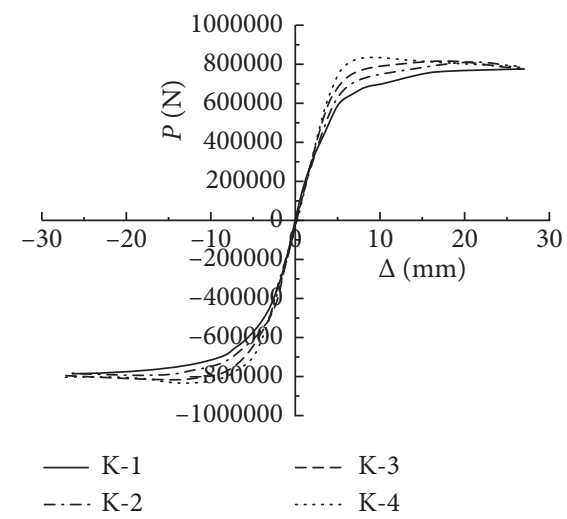

FIGURE 7: Skeleton curves of frames with various concrete strength levels.

stiffness of the reinforced concrete frame (with shaped columns) increased by 15\% 20\%. The stiffness degradation curves of frames with smaller concrete strengths were flatter, with a longer descent stage, which was related to the improved energy dissipation capacity of frames, because of their reduced concrete strength, and therefore, they exhibited better seismic performance.

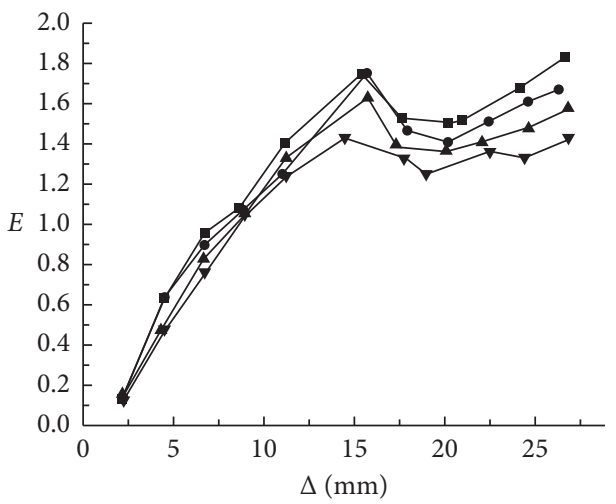

$$
\begin{array}{ll}
\rightarrow \mathrm{K}-1 & \rightarrow \mathrm{K}-3 \\
\rightarrow \mathrm{K}-2 & \rightarrow \mathrm{K}-4
\end{array}
$$

FIGURE 8: Curves of coefficients of energy dissipation with various concrete strength levels.

\subsection{Reinforcement Ratio}

4.2.1. Effects of Reinforcement Ratio on the Energy Dissipation Capacity of the Frame. The hysteresis curves of a reinforced concrete frame with shaped columns, with various 


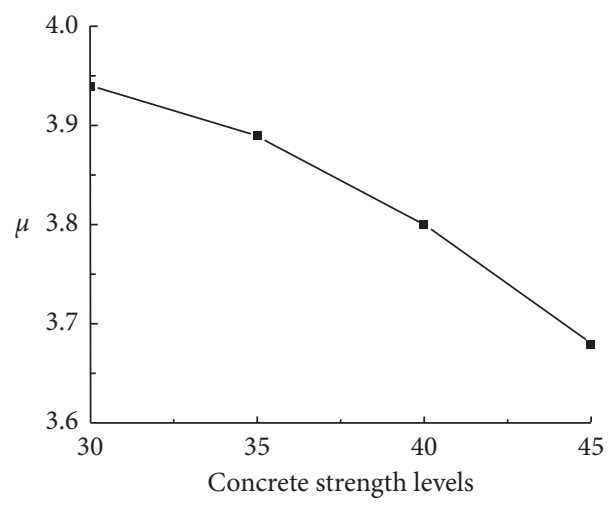

FIGURE 9: Relationship between various concrete strength levels and ductility coefficients.

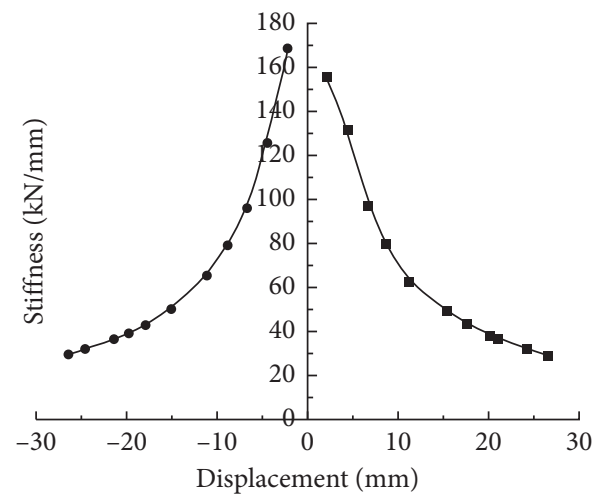

(a)

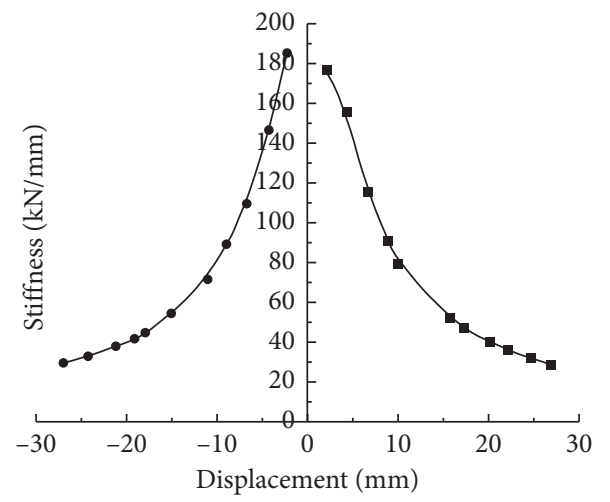

(c)

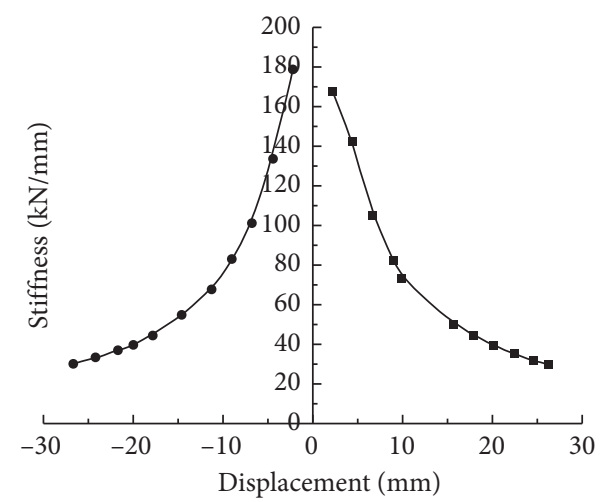

(b)

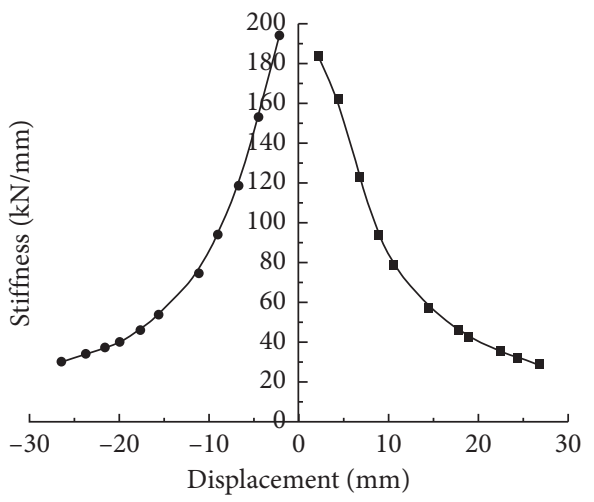

(d)

Figure 10: Stiffness degradation curves of frames with various concrete strengths. (a) K-1. (b) K-2. (c) K-3. (d) K-4.

reinforcement ratios, under low reversed cyclic loading, are shown in Figure 11. The related skeleton curves that were obtained are shown in Figure 12.

As shown in Figure 11, reinforced concrete frames with shaped columns exhibited strong plastic deformation capacities and good seismic performance and energy dissipation capacities. As shown in Figure 12, with increasing reinforcement ratios for reinforced concrete frames with shaped columns, the deformation capacity became better and better and their ductility became stronger and stronger.

According to Figure 11, the coefficients of energy dissipation were calculated for frames with shaped columns with various reinforcement ratios, based on which curves reflecting the relationship were obtained between various reinforcement ratios and the coefficients of energy dissipation of the frames, as shown in Figure 13.

According to Figure 13, the relationship can be found between the energy dissipation curves of reinforced concrete frame structures with shaped columns. This indicates that energy dissipation occurs mainly after the column frame yields. During the later period of loading, energy dissipation coefficient slowly increased, and even slightly decreased, because of accumulated damage. However, the energy dissipation coefficient increased with an increase in the 


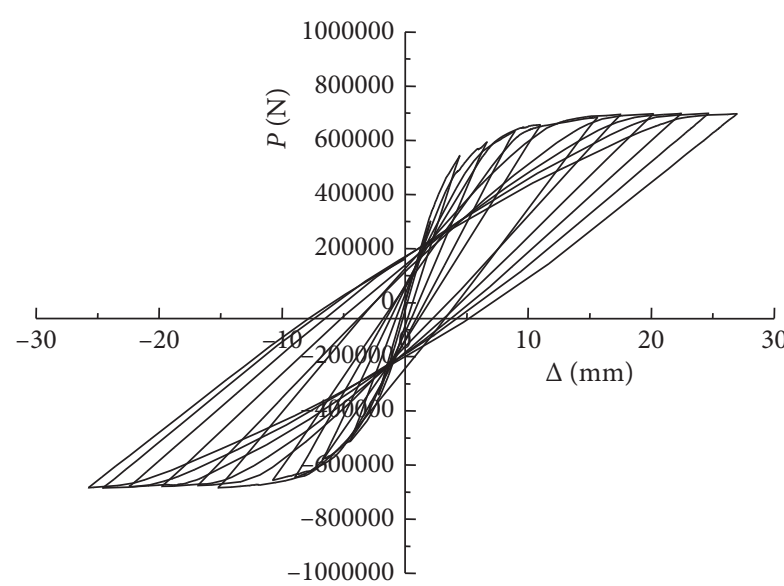

(a)

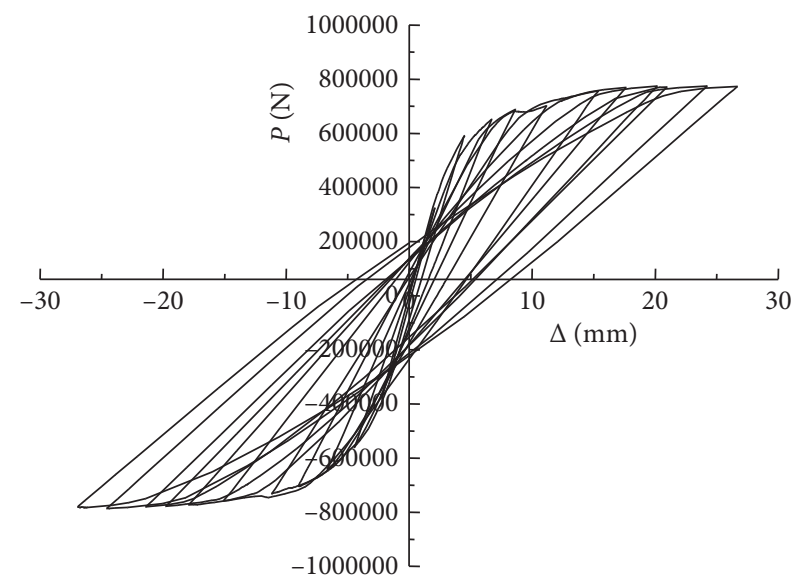

(c)

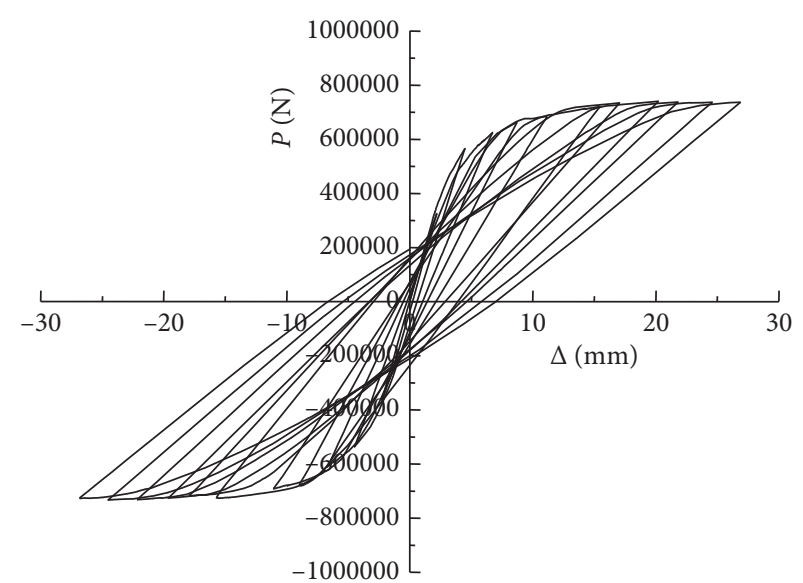

(b)

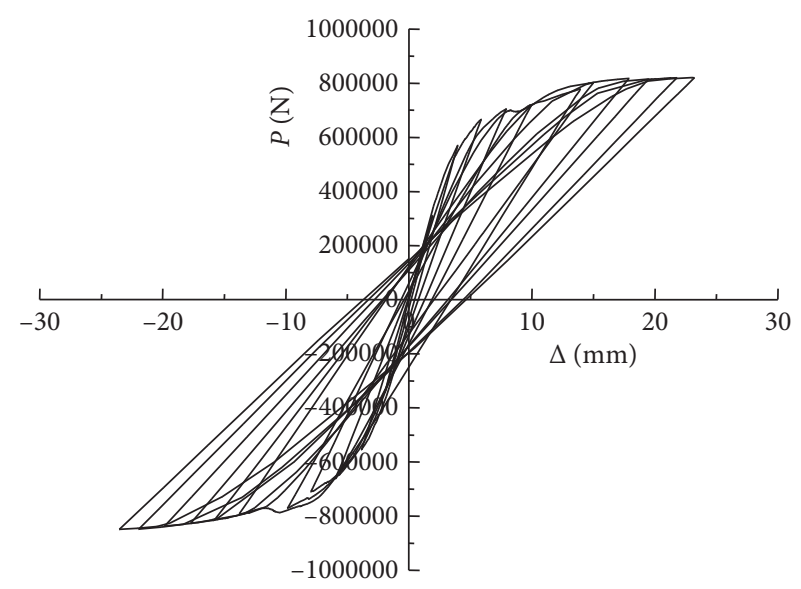

(d)

Figure 11: Hysteresis curves of frames with various reinforcement ratios. (a) K-5. (b) K-6. (c) K-1. (d) K-7.

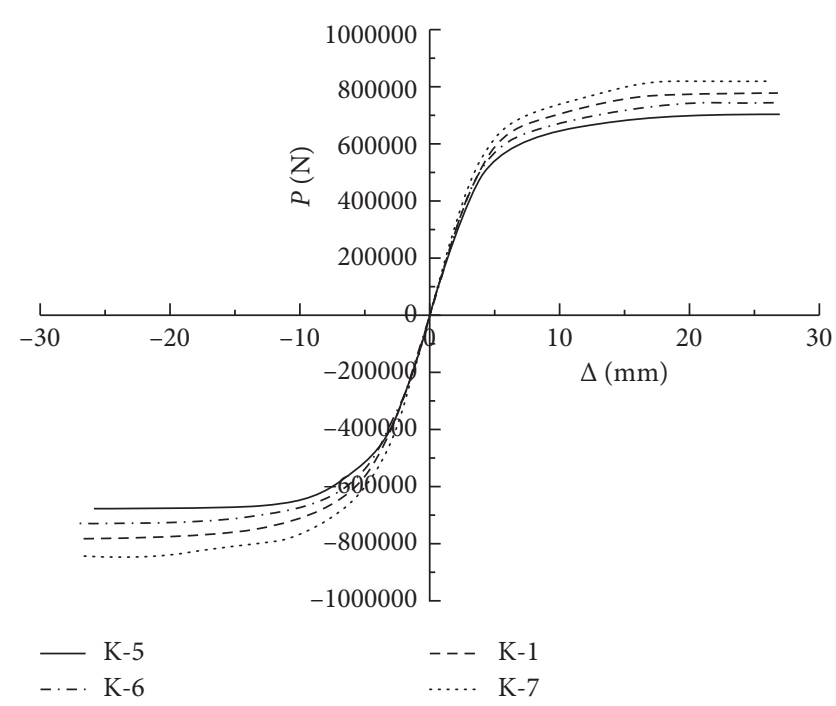

FIGURE 12: Skeleton curves of frames with various reinforcement ratios.

reinforcement ratio of the reinforced concrete frame and columns. Relative to a single specimen, the amplitude increase in the energy dissipation coefficient was larger,

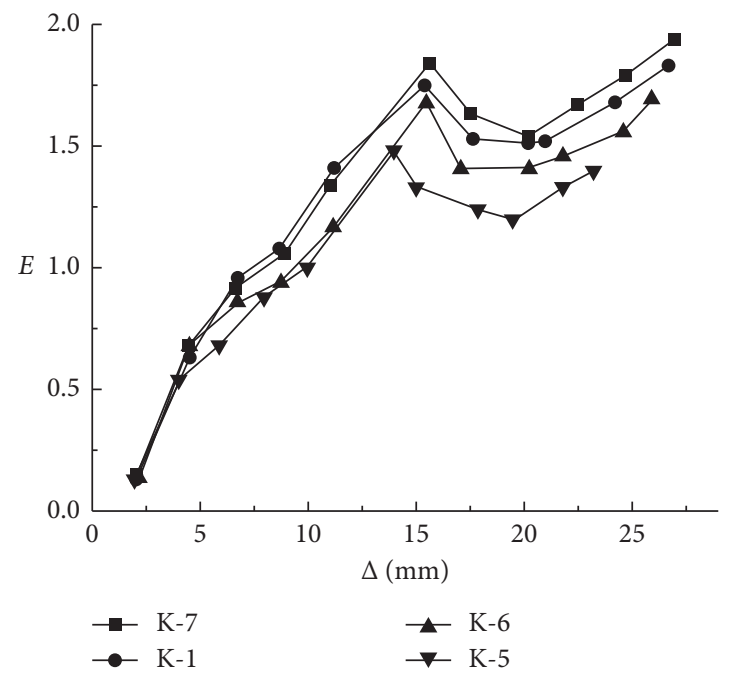

Figure 13: Curves of coefficients of energy dissipation for various reinforcement ratios.

indicating that an increase in reinforcement ratio was beneficial for energy dissipation capacity of the reinforced frame and column structure. 
4.2.2. Effects of Reinforcement Ratio on the Deformation Performance of the Frame. According to Figure 12, the ductility coefficients of the reinforced concrete frame and column structures were calculated, based on which curves were obtained reflecting the relationship between various reinforcement ratios and ductility coefficients of frame and column combinations, as shown in Figure 14.

From the curve shown in Figure 14, it can be observed that, with the increase in the reinforcement ratio of the concrete in the reinforced structure, its deformation performance gradually increased.

4.2.3. Effects of Reinforcement Ratio on the Stiffness Degradation Performance of the Frame. According to equation (2) and Figure 11, the values of the stiffness of reinforced concrete frames with shaped columns were calculated, based on which curves were obtained reflecting the relationship between reinforcement ratios and frame stiffness degradation under varying displacement, as is shown in Figure 15.

As shown in Figure 15, stiffness degradation curves are shown where the concrete strength and axial compression ratio were maintained constant, but with the increasing reinforcement ratio in the frames, initial stiffness increased significantly and residual stiffness also increased. Residual stiffness can be used to measure accumulated damage of specimens, where positive residual stiffness is smaller than negative residual stiffness.

\subsection{Axial Compression Ratio}

4.3.1. Effects of Axial Compression Ratio on the Energy Dissipation Capacity of the Frame. The hysteresis curves of frames with various axial compression ratios under low reversed cyclic loading are shown in Figure 16. From these, the skeleton curves of frames with shaped columns were obtained, as shown in Figure 17.

The reinforced concrete frame structures with shaped columns exhibited relatively strong plastic deformation capacities, as shown in Figure 16, which equated to good seismic performance and energy dissipation capacities. As shown in Figure 17, with increasing axial compression ratios, the peak capacities of reinforced concrete frames with shaped columns increased gradually with corresponding decreased displacements, indicating that the ductility of the frames became progressively weaker.

According to Figure 16, the coefficient of energy dissipation was calculated for frames with shaped columns, with various axial compression ratios. Based on the results, curves reflecting the relationship between various axial compression ratios and coefficients of energy dissipation were obtained for frames with shaped columns, as shown in Figure 18.

The relationship between the energy dissipation curves of frame structures with shaped columns can be derived from Figure 18. These indicate that energy dissipation occurred mainly after yielding of the frame. During the later period of loading, the energy dissipation coefficient

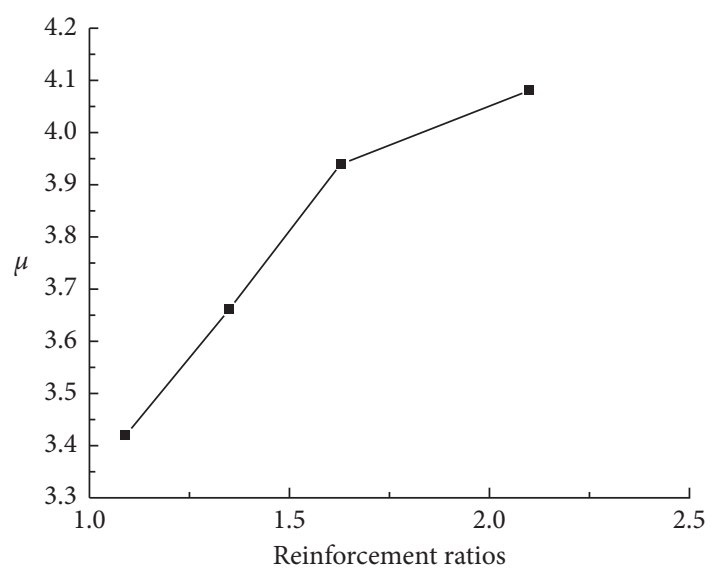

Figure 14: Relationship between various reinforcement ratios and ductility coefficients.

increased slowly, and even decreased slightly, because of accumulating damage. However, the energy dissipation coefficient decreased with the increase of the axial compression ratio. Relative to a single specimen, the amplitude increase in the energy dissipation coefficient was much larger, indicating that the decrease in axial compression ratios could enhance the energy dissipation capacity of the frames. Meantime, however, energy dissipation curves of frames with high axial compression ratios were relatively short, which indicated that these frames were lacking in sustained energy dissipation capacity.

\subsubsection{Effects of Axial Compression Ratio on the Deformation} Performance of the Frame. According to Figure 18, the ductility coefficients of reinforced concrete frames with shaped columns were calculated, based on which curves reflecting the relationship between various axial compression ratios and the ductility coefficient of the reinforced concrete frame were obtained, as shown in Figure 19.

Figure 19 shows that, with increasing axial compression ratios in a reinforced concrete frame, its deformation performance gradually decreased and its seismic performance reduced.

\subsubsection{Effects of Axial Compression Ratio on the Stiffness} Degradation Performance of the Frame. According to equation (2) and Figure 16, the stiffness value of a reinforced concrete frame was calculated, based on which curves were obtained that reflected the relationship between axial compression ratios and the stiffness degradation of a frame when displacement was varied, as shown in Figure 20.

As shown in Figure 20, the stiffness degradation curves of four reinforced concrete frame structures could be divided into three different stages. If the concrete strength and reinforcement ratio were kept constant, an increase in the axial compression ratio was beneficial for shear capacity, while a decrease in the axial compression ratio was beneficial for energy dissipation capacity, deformation performance, and stiffness degradation. 


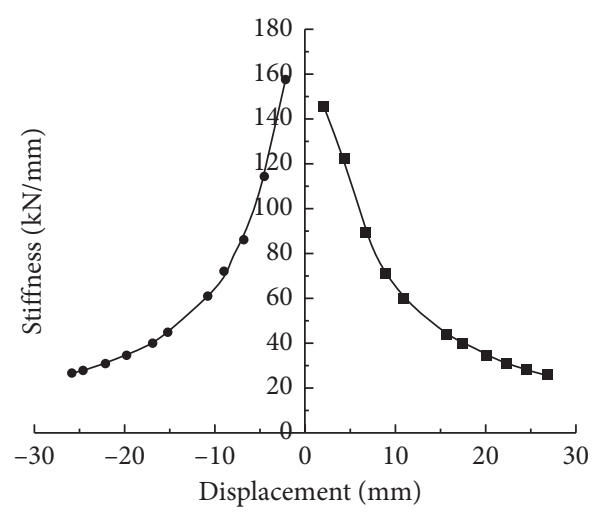

(a)

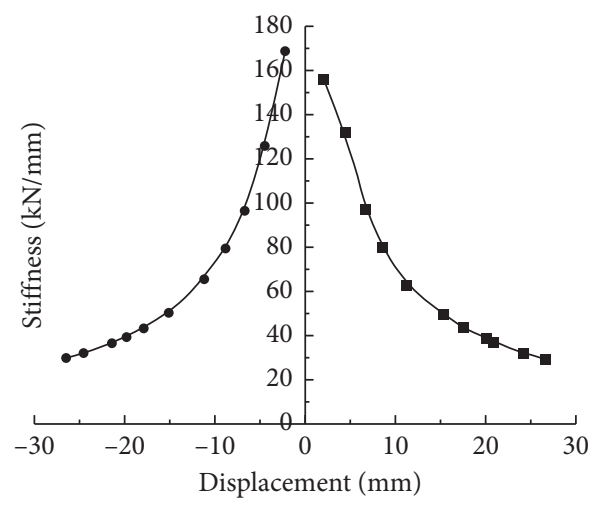

(c)

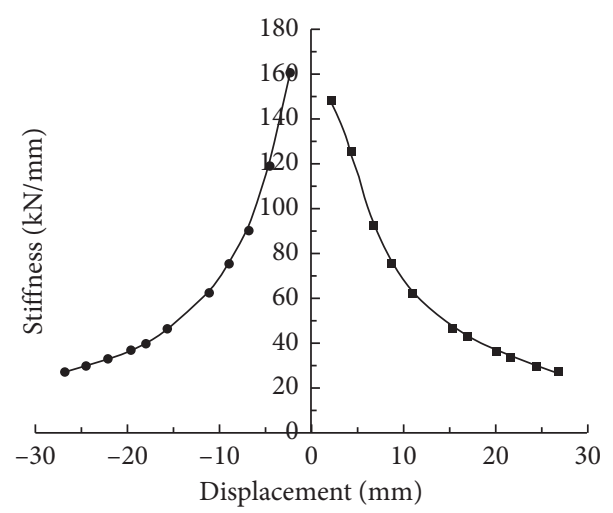

(b)

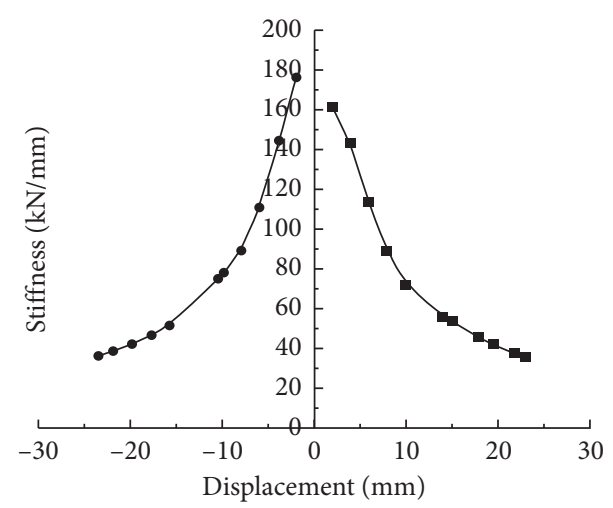

(d)

FiguRE 15: Stiffness degradation curves of frames with various reinforcement ratios. (a) K-5. (b) K-6. (c) K-1. (d) K-7.

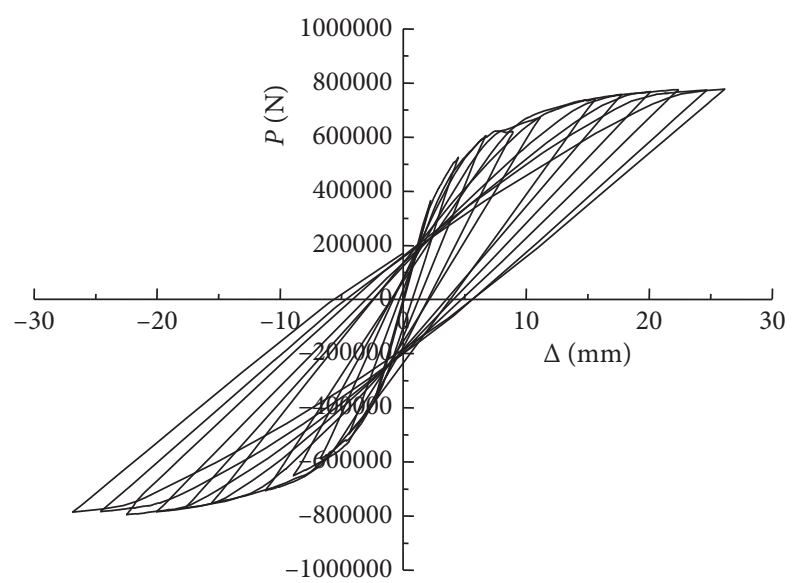

(a)

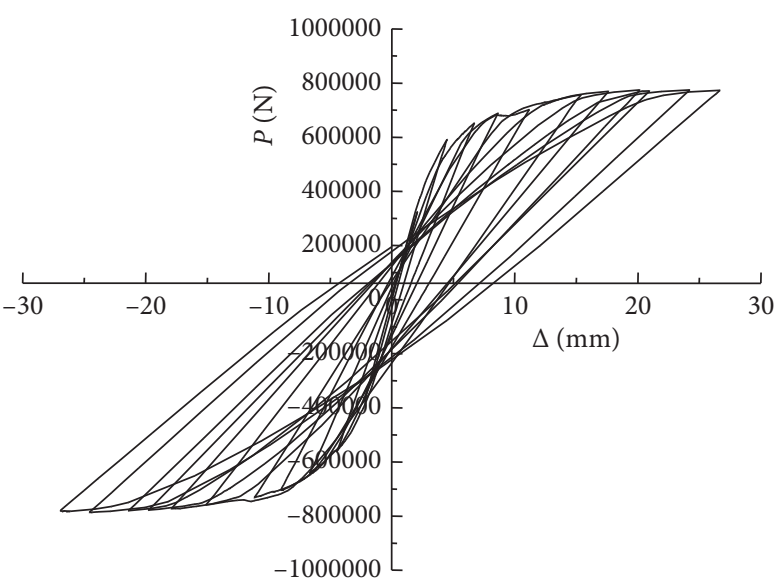

(b)

Figure 16: Continued. 


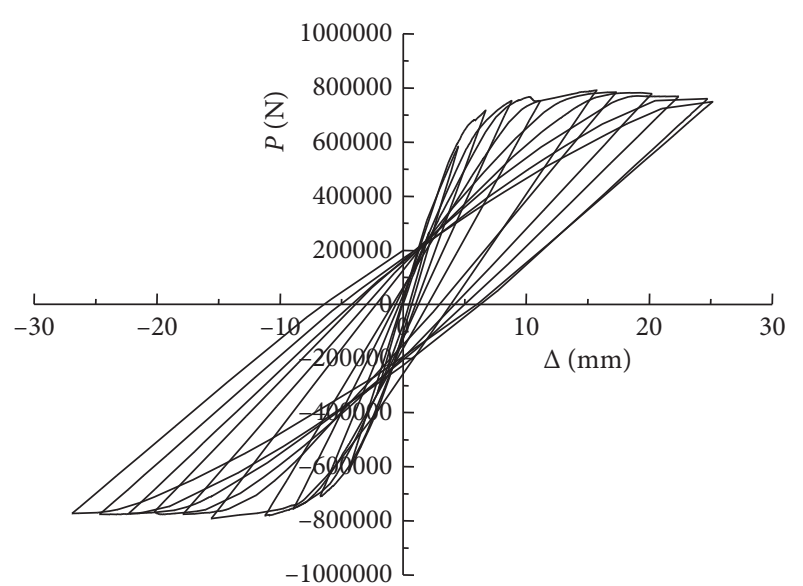

(c)

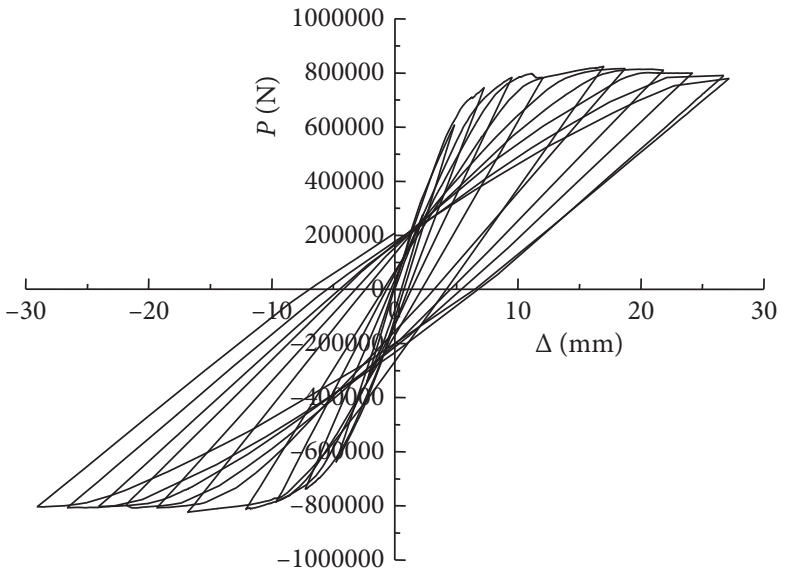

(d)

Figure 16: Hysteresis curves of frames with various axial compression ratios. (a) K-8. (b) K-1. (c) K-9. (d) K-10.

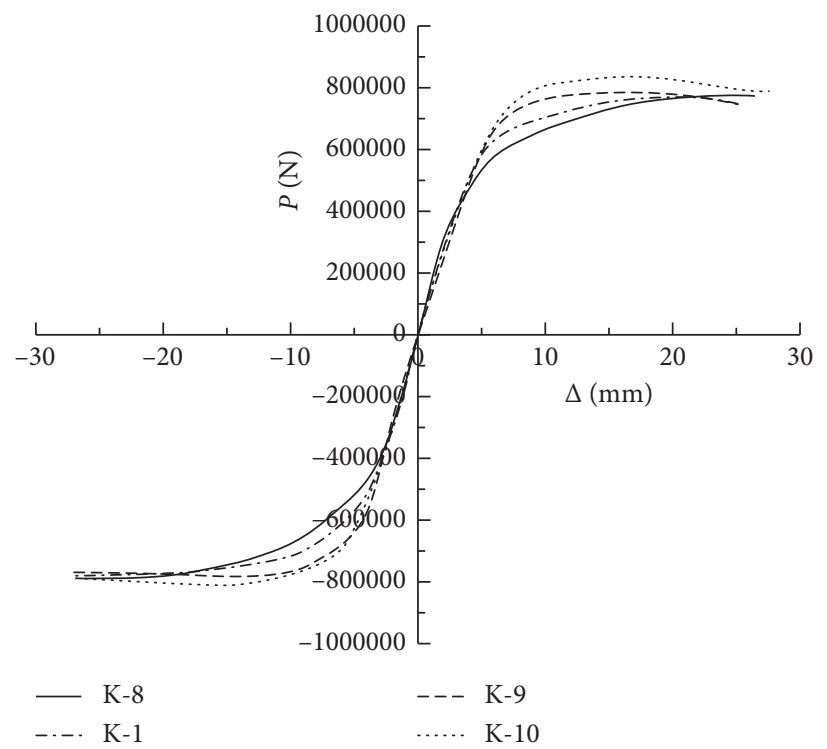

FIGURE 17: Skeleton curves of frames with various axial compression ratios.

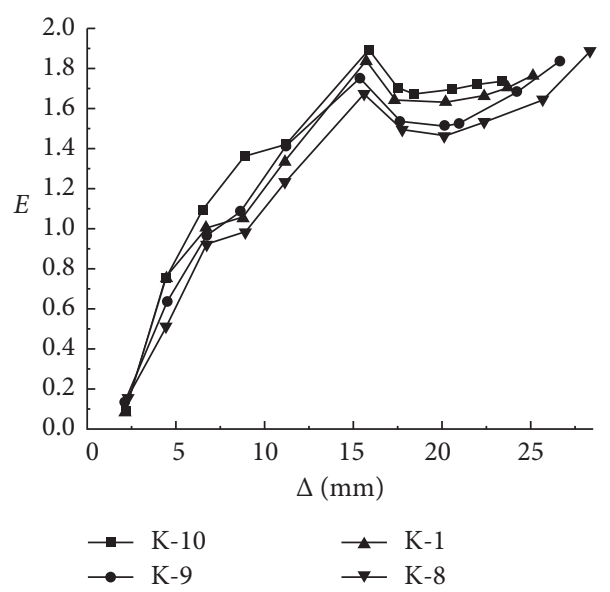

Figure 18: Curves of coefficients of energy dissipation for various axial compression ratios. 


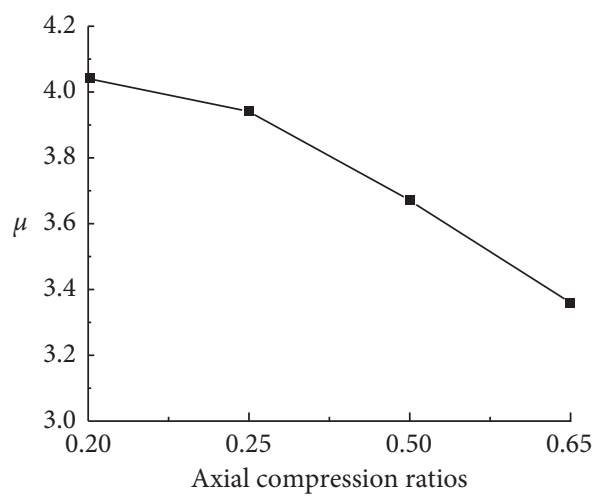

FIGURE 19: Relationship between various axial compression ratios and ductility coefficients.

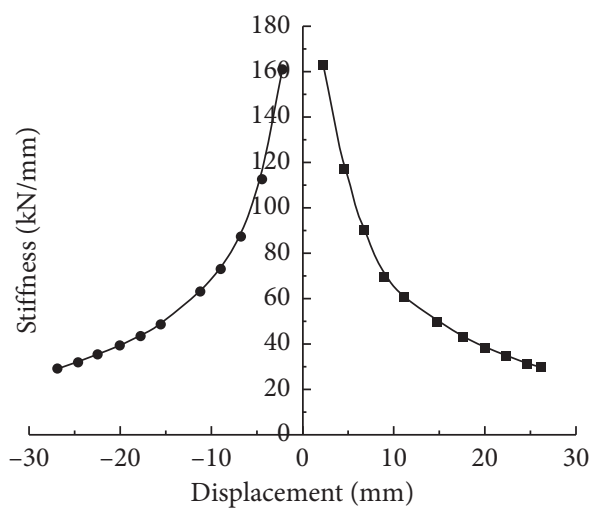

(a)

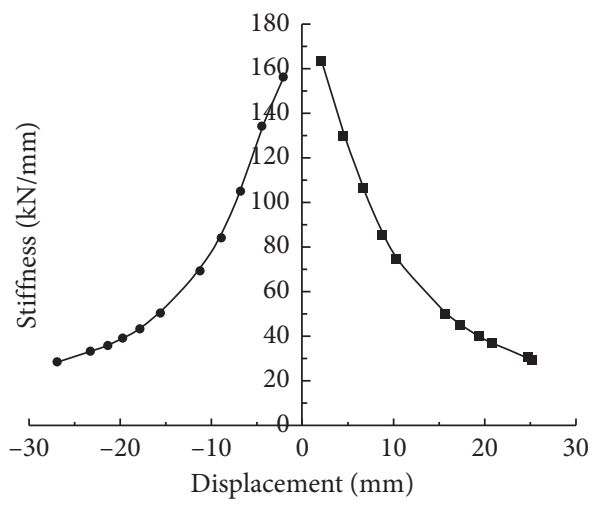

(c)

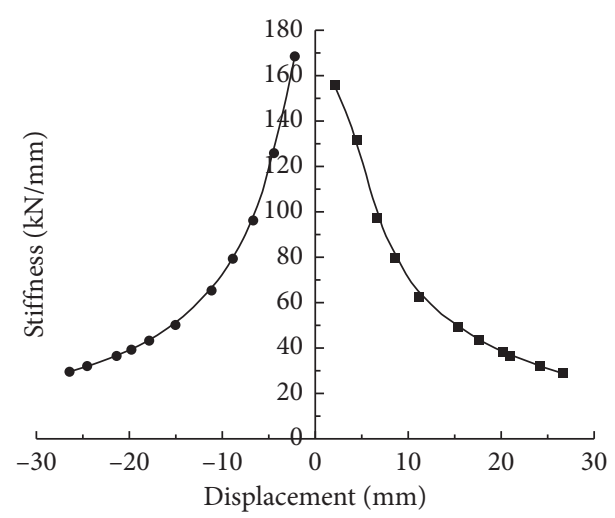

(b)

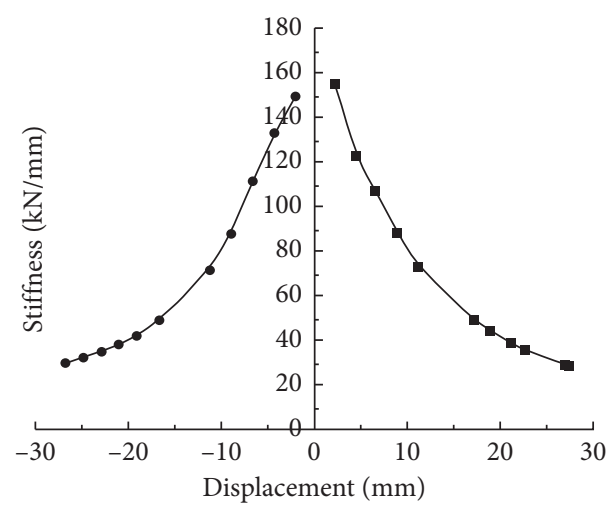

(d)

Figure 20: Stiffness degradation curves of frames with various axial compression ratios. (a) K-8. (b) K-1. (c) K-9. (d) K-10.

\section{Conclusions}

Numerical simulation analysis was performed on a tenframe structure with specially shaped columns under low reversed cyclic loading, according to which the following conclusions were drawn:

(1) In reinforced concrete frame structures with shaped columns, with an increase in the strength of concrete, the peak load gradually increased, presenting arced hysteresis curves. Energy dissipation capacity and deformation capacity were gradually decreased, and there was an increase of $15-20 \%$ over the initial stiffness value. The stiffness degradation curves of frames with smaller concrete strengths were flatter, with a longer descent stage, and they exhibited better seismic performance.

(2) In reinforced concrete frame structures with specially shaped columns, increasing the reinforcement ratio gradually increased the peak load, resulting in arced hysteresis curves with a relatively broad hysteresis loop. The energy dissipation capacity and deformation capacity were gradually increased, and initial stiffness was increased by approximately $10 \%$. The slopes of the slow descent stage and descent stage 
were relatively smaller, which delayed the failure of the specimens.

(3) In reinforced concrete frame structures with specially shaped columns, with an increase in the axial compression ratio, the peak load was increased significantly, and arced hysteresis curves were evident with fuller hysteresis loops when the axial compression ratio was smaller. The energy dissipation capacity and deformation capacity of the structure were gradually decreased, and the initial stiffness value was decreased by approximately $28 \%$. A smaller axial compression ratio can limit the development of damage and delayed the failure of the specimens.

\section{Nomenclature}

\begin{tabular}{|c|c|}
\hline HRB335: & $\begin{array}{l}\text { Representation of the mechanical } \\
\text { properties and size specification of the } \\
\text { screw steel with a tensile yield strength of } \\
335 \mathrm{MPa}\end{array}$ \\
\hline $\begin{array}{l}\text { Axial } \\
\text { compression } \\
\text { ratio: }\end{array}$ & $\begin{array}{l}\text { Axial compression design value of } \\
\text { columns/total section area multiplied by } \\
\text { the design value of the axial compressive } \\
\text { strength of the concrete }\end{array}$ \\
\hline $\begin{array}{l}\text { Reinforcement } \\
\text { ratio: }\end{array}$ & $\begin{array}{l}\text { Area of longitudinal reinforcement of a } \\
\text { reinforced concrete member/effective } \\
\text { total area of the component }\end{array}$ \\
\hline$\omega:$ & Maximum earthquake intensity \\
\hline$\varepsilon:$ & Peak strength of the curve \\
\hline$x:$ & $\begin{array}{l}\text { Earthquake intensity (for determination } \\
\text { of seismic intensity) providing criteria for } \\
\text { the evaluation of seismic fortifications }\end{array}$ \\
\hline$k:$ & Shape parameter \\
\hline$\Delta:$ & Displacement applied to the structure \\
\hline$\mu:$ & $\begin{array}{l}\text { Ductility coefficient which is the ratio of } \\
\text { maximum deformation to yield } \\
\text { deformation }\end{array}$ \\
\hline$E:$ & Energy dissipation coefficient. \\
\hline
\end{tabular}

\section{Data Availability}

The research data used to support the findings of this study are included within the article.

\section{Conflicts of Interest}

The authors declare that there are no conflicts of interest regarding the publication of this article.

\section{Acknowledgments}

The authors gratefully acknowledge the project support from the National Natural Science Foundation of China (No. 51578120) and the Graduate Science and Technology Innovation Projects in Northeast Petroleum University (YJSCX2017-025NEPU).

\section{References}

[1] K.-W. Li, G.-H Liu, and X. Wan, "Research on seismic behavior of high-performance steel reinforced concrete crossshaped column," Earthquake Resistant Engineering and Retrofitting, vol. 37, no. 6, pp. 8-14, 2015.

[2] J. Song and Y.-F. Xu, "Finite element analysis of seismic behavior of cross-shaped concrete-filled steel tube core column under reversed loading," in Proceedings of the 11st National Symposium on modern structural engineering of China, pp. 1058-1059, Shanghai, China, June 2011.

[3] X.-Z. Diao and Y.-F. Xu, "Experimental study on eccentrically compressed cross-shaped steel reinforced concrete columns," Progress in Steel Building Structures, vol. 13, no. 2, pp. 44-50, 2011.

[4] Y.-J. Shao, Z.-P. Chen, and J.-Y. Xue, "Experimental research and theoretical analyses on axial compression ratio of steel reinforced concrete special-shaped columns," Journal of Building Structures, vol. 28, no. 6, pp. 153-159, 2007.

[5] M. Mohammadhassani, S. Akib, M. Shariati, M. Suhatril, and M. M. Arabnejad Khanouki, "An experimental study on the failure modes of high strength concrete beams with particular references to variation of the tensile reinforcement ratio," Engineering Failure Analysis, vol. 41, pp. 73-80, 2014.

[6] M. Shariati, A. Shariati, N. H. Ramli Sulong, M. Suhatril, and M. M. Arabnejad Khanouki, "Fatigue energy dissipation and failure analysis of angle shear connectors embedded in high strength concrete," Engineering Failure Analysis, vol. 41, pp. 124-134, 2014.

[7] A. Shariati, N. H. R. Sulong, M. Suhatril, and M. Shariati, "Investigation of channel shear connectors for composite concrete and steel T-beam," International Journal of Physical Sciences, vol. 7, no. 11, pp. 1828-1831, 2012.

[8] M. Shariati, N. H. Ramli Sulong, A. Shariati, and A. B. H. Kueh, "Comparative performance of channel and angle shear connectors in high strength concrete composites: an experimental study," Construction and Building Materials, vol. 120, pp. 382-392, 2016.

[9] S. N. R. Shah, N. H. R. Sulong, M. Shariati, and M. Z. Jumaat, "Steel rack connections: identification of most influential factors and a comparison of stiffness design methods," PLos One, vol. 10, no. 10, Article ID e0139422, 2015.

[10] C.-X. Xu, X.-Q. Liu, G.-F. Du, and J.-C. Zhang, "Comparison and analysis on seismic behavior of interior joints in the composite frame consisting of CFST crisscross section columns and steel beams," Journal of Wuhan University of Technology, vol. 8, pp. 118-122, 2012.

[11] F.-L. Qu, C.-K. Huang, and X. Zhao, "Nonlinear analysis of special-shaped reinforced concrete columns," Journal of Hefei University of Technology, vol. 49, no. 2, pp. 234-238, 2009.

[12] M. Shariati, N. H. Ramli Sulong, A. Shariati, and M. A. Khanouki, "Behavior of V-shaped angle shear connectors: experimental and parametric study," Materials and Structures, vol. 49, no. 9, pp. 3909-3926, 2016.

[13] A. Toghroli, M. Suhatril, Z. Ibrahim, M. Safa, and M. Shariati, "Potential of soft computing approach for evaluating the factors affecting the capacity of steel-concrete composite beam," Journal of Intelligent Manufacturing, vol. 29, no. 8, pp. 1793-1801, 2016.

[14] M. Mohammadhassani, M. Suhatril, M. Shariati, and F. Ghanbari, "Ductility and strength assessment of HSC beams with varying of tensile reinforcement ratios," Structural Engineering and Mechanics, vol. 48, no. 6, pp. 833-848, 2013. 
[15] M. M. A. Khanouki, N. H. Ramli Sulong, M. Shariati, and M. M. Tahir, "Investigation of through beam connection to concrete filled circular steel tube (CFCST) column," Journal of Constructional Steel Research, vol. 121, pp. 144-162, 2016.

[16] Ministry of Construction of the People's Republic of China, Technical Specification for Concrete Structures with Specially Shaped Columns (JGJ 149-2006), Profession Standard of the People's Republic of China, Beijing, China, 2006.

[17] J. Mazars and G. Pijaudier-Cabot, "Continuum damage theory-application to concrete," Journal of Engineering Mechanics, vol. 115, no. 2, pp. 345-365, 1989.

[18] J. D. Clayton, "A model for deformation and fragmentation in crushable brittle solids," International Journal of Impact Engineering, vol. 35, no. 5, pp. 269-289, 2008.

[19] Q. Z. Sun, "Plastic damage model of ABAQUS concrete," Chongqing Architecture | Chongqing Archit, vol. 11, pp. 70-72, 2014.

[20] M. Shariati, N. H. Ramli Sulong, M. Suhatril, and S. Ali, "Behaviour of C-shaped angle shear connectors under monotonic and fully reversed cyclic loading: an experimental study," Materials and Design, vol. 41, pp. 67-73, 2017.

[21] M. Shariati, N. H. Ramli Sulong, N. H. Ramli Sulong et al., "Behavior of channel shear connectors in normal and light weight aggregate concrete (experimental and analytical study)," Advanced Materials Research, vol. 168-170, pp. 2303-2307, 2010.

[22] M. Safa, M. Shariati, Z. Ibrahim et al., "Potential of adaptive neuro fuzzy inference system for evaluating the factors affecting steel-concrete composite beam's shear strength," Steel and Composite Structures, vol. 21, no. 3, pp. 679-688, 2016.

[23] Y. Yang, Y.-B. Wu, and Y.-F. Zhang, "Effect of concrete strength to mechanical performance of GFRP-concrete-steel tubular composite columns," Journal of Zhengzhou University (Natural Science Edition), vol. 48, no. 3, pp. 118-123, 2016.

[24] Y.-P. Shi and Y.-R. Zhou, Example Explanations of ABAQUS Finite Element Analysis, 2nd Version, China Machine Press, Beijing, China, 2012.

[25] G.-B. Liu, Seismic Performance Analysis of Reinforced Concrete Special-Shaped Columns, Chongqing Jiaotong University, Chongqing, China, 2013.

[26] X.-J Cai, H.-X Jia, M.-H Gong, and S.-Z Tian, "Hybrid experimental study on seismic behavior of steel reinforced concrete frame with special-shaped columns based on singlecolumn structure model," Journal of Building Structures, vol. 38, no. 4, pp. 35-44, 2017.

[27] S. N. R. Shah, N. H. Ramli Sulong, R. Khan, M. Z. Jumaat, and M. Shariati, "Behavior of industrial steel rack connections," Mechanical Systems and Signal Processing, vol. 70-71, pp. 725-740, 2016.

[28] I. Mansouri, M. Shariati, M. Safa, Z. Ibrahim, and M. M. Tahir, "Analysis of influential factors for predicting the shear strength of a V-shaped angle shear connector in composite beams using an adaptive neuro-fuzzy technique," Journal of Intelligent Manufacturing, vol. 30, no. 3, pp. 1247-1257, 2017.

[29] M. Mohammadhassani, H. Nezamabadi-pour, M. Suhatril, and M. Shariati, "An evolutionary fuzzy modelling approach and comparison of different methods for shear strength prediction of high-strength concrete beams without stirrups," Smart Structures and Systems, vol. 14, no. 5, pp. 785-809, 2014.

[30] M. Shariati, N. H. Sulong, S. Maleki, and M. M. Kn, "Experimental and analytical study on channel shear connectors in light weight aggregate concrete," in Proceedings of the Steel \& Composite Structures-Proceedings of the 4th International Conference, pp. 293-298, Sydney, Australia, 2010.
[31] T.-T. Liang, "Determination method of earthquake action with arbitrary exceeding probability," Structural Engineers, vol. 4, pp. 135-138, 2015. 


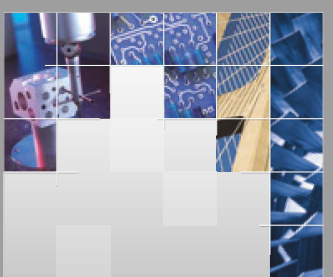

\section{Enfincering}
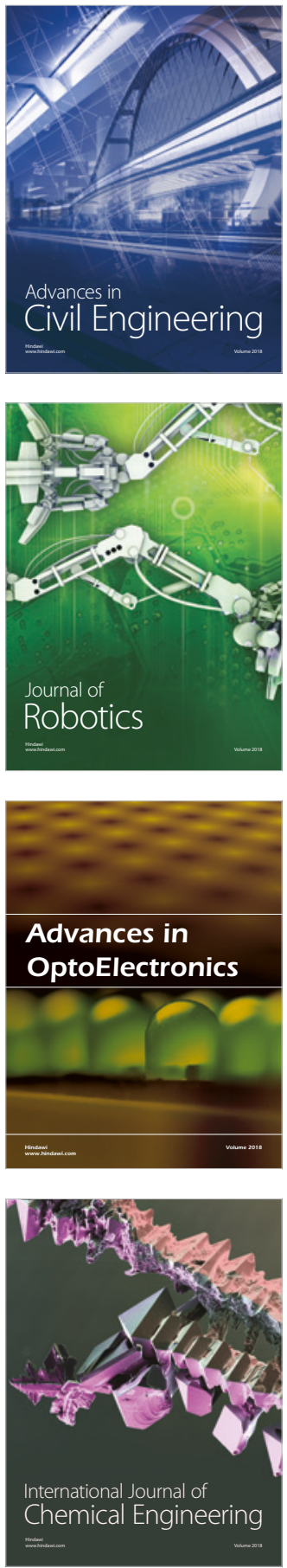

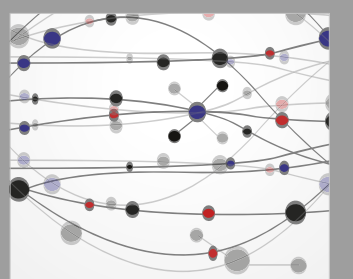

\section{Rotating \\ Machinery}

The Scientific World Journal

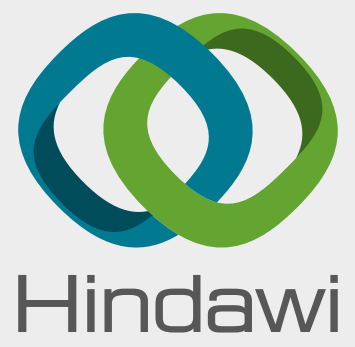

Submit your manuscripts at

www.hindawi.com
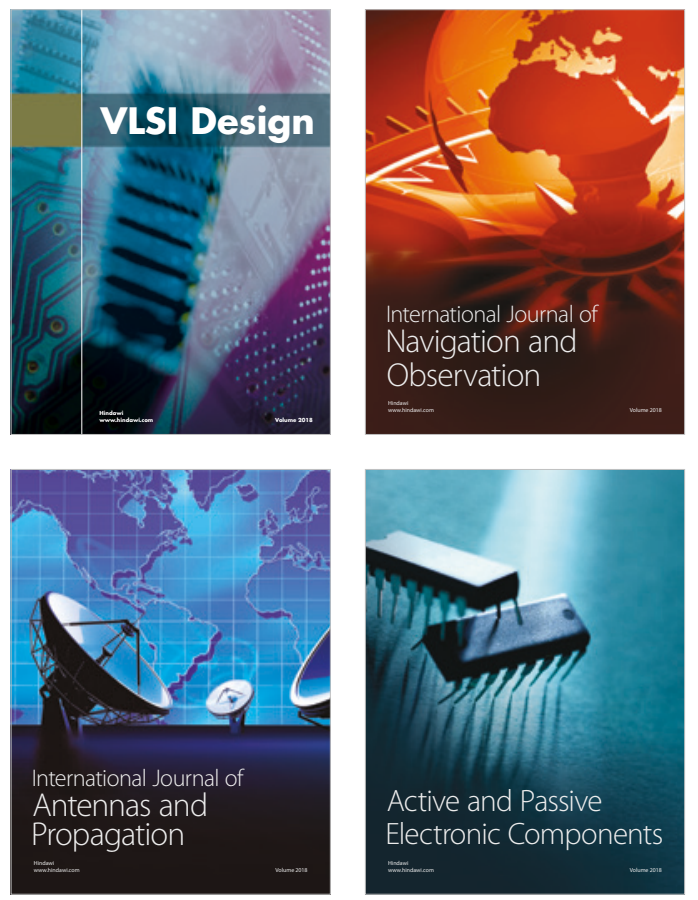
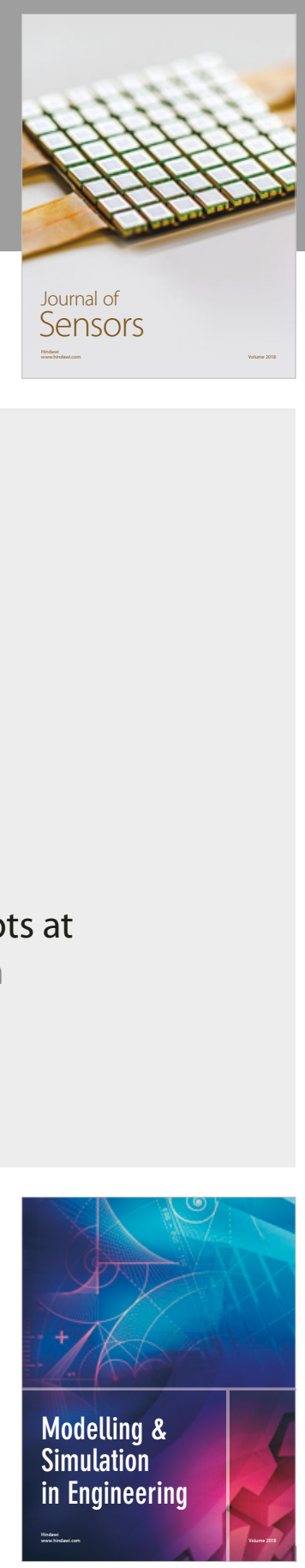

\section{Advances \\ Multimedia}
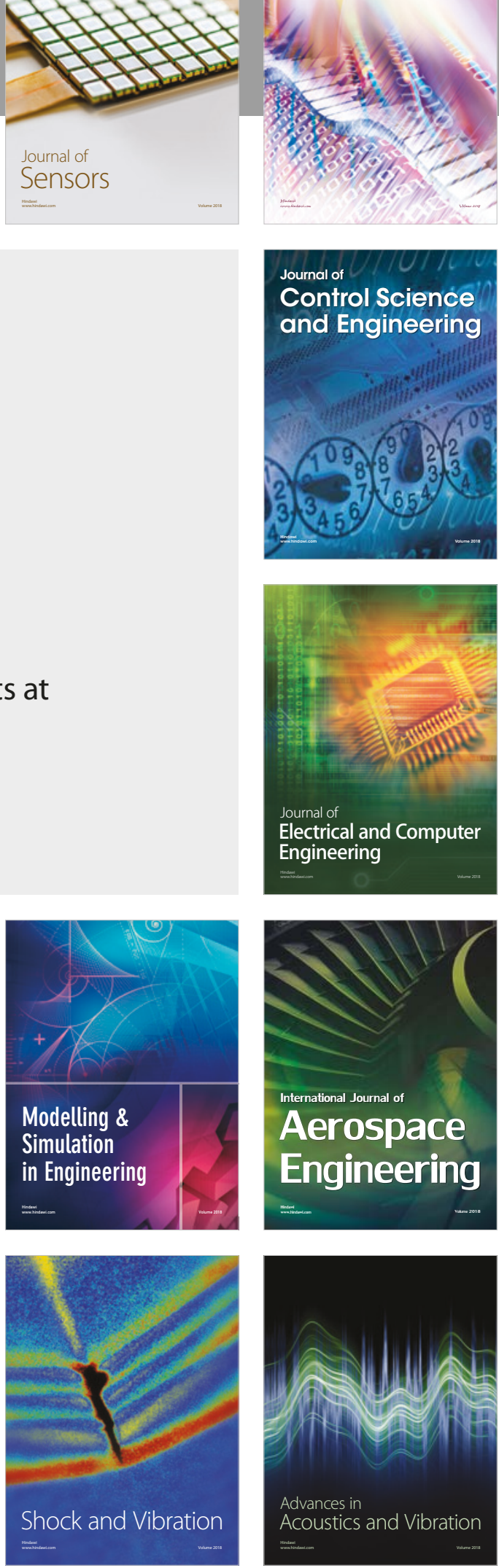